\title{
Research misconduct in the fields of ethics and philosophy: researchers' perceptions in Spain
}

\author{
Ramón A. Feenstra ${ }^{1}$, Emilio Delgado López-Cózar ${ }^{2}$ and Daniel Domínguez-Pallarés ${ }^{3}$
}

\begin{abstract}
Empirical studies have revealed a disturbing prevalence of research misconduct in a wide variety of disciplines, although not, to date, in the areas of ethics and philosophy. This study aims to provide empirical evidence on perceptions of how serious a problem research misconduct is in these two disciplines in Spain, particularly regarding the effects that the model used to evaluate academics' research performance may have on their ethical behaviour. The methodological triangulation applied in the study combines a questionnaire, a debate at the annual meeting of scientific association, and in-depth interviews. Of the 541 questionnaires sent out, 201 responses were obtained (37.1\% of the total sample), with a significant difference in the participation of researchers in philosophy (30.5\%) and in ethics (52.8\%); 26 researchers took part in the debate and 14 interviews were conducted. The questionnaire results reveal that $91.5 \%$ of the respondents considered research misconduct to be on the rise; $63.2 \%$ considered at least three of the fraudulent practices referred to in the study to be commonplace, and $84.1 \%$ identified two or more such practices. The researchers perceived a high prevalence of duplicate publication $(66.5 \%)$ and self-plagiarism $(59.0 \%)$, use of personal influence $(57.5 \%)$ and citation manipulation $(44.0 \%)$, in contrast to a low perceived incidence of data falsification or fabrication $(10.0 \%)$. The debate and the interviews corroborated these data. Researchers associated the spread of these misconducts with the research evaluation model applied in Spain.
\end{abstract}

\section{Keywords}

Research misconduct; ethics; philosophy; evaluation policy; Spain; selfplagiarism

Important notice: This is the Author's Original Manuscript (AOM) (also called a "preprint") sent to review to Science and Engineering Ethics on 11/10/2020. The final version of the article was published online at SEE on 21/01/2021. The online version is available at: https://doi.org/10.1007/s11948-021-00278-w

Feenstra, R.A., Delgado López-Cózar, E. \& Pallarés-Domínguez, D. (2021) Research Misconduct in the Fields of Ethics and Philosophy: Researchers' Perceptions in Spain. Science and Engineering Ethics, 27, 1.

\footnotetext{
${ }^{1}$ Universitat Jaume I de Castelló (Spain)

${ }^{2}$ Universidad de Granada (Spain)

${ }^{3}$ Universitat Jaume I de Castelló (Spain)

Ramón A. Feenstra

feenstra@uji.es
} 


\section{Introduction}

Numerous studies have been published in recent years examining the extent, scope, frequency and typology of research misconduct (Martinson et al. 2005; De Vries et al. 2006; Fanelli 2009; Pupovac and Fanelli 2015; Gross 2016; Pupovac et al. 2017; Haven et al. 2019a). This research has mainly focused on biomedical and health sciences, and other experimental sciences (Jefferson 1998; Gilbert and Denison 2003; De Vries et al. 2006, Anderson et al. 2007; Stretton et al. 2012; Okonta and Rossouw 2013; DuBois et al. 2013; Dhingra and Mishra 2014; Tijdink et al. 2014; Rohwe et al. 2017; Buljan et al. 2018; Godecharle et al. 2018; Liao et al. 2018; Grey et al. 2019; Marco-Cuenca et al. 2019; Dal-Ré 2020; Kokiwar et al. 2020). By contrast, fewer studies have specifically examined the prevalence of research misconduct in the social sciences (Bedeian et al. 2010; John et al. 2012; Fonseca-Mora et al. 2014; Moctezuma 2016; Hopp and Hoover 2017; Bayley 2019), and even less so in the humanities, although some authors have included some humanistic fields in multidisciplinary analyses (Bretag and Carapiet 2007; Krstić 2015; Pupovac et al. 2017; Horbach and Halffman 2019; Haven et al. 2019a; Haven et al. 2019b; Haven et al. 2019c).

Empirical studies specifically examining the prevalence of research misconduct in the fields of ethics and philosophy are glaringly absent from this literature, especially in light of their crucial role in scientific integrity. This topic has recently begun to attract some research attention, notably in studies analysing the occasional notorious cases and episodes of research misconduct in philosophy (Hansson 2017; Zwart 2017; Dougherty 2018). Likewise, reflections are now being published on the ethical implications of research in philosophy and ethics (Hansson 2017), on the conceptual definition and clarification of misconduct in these fields, and especially on the challenges of accurately defining and detecting plagiarism in the field of philosophy (Hansson 2008; Hansson 2015; Dougherty 2018). Other studies also examine the problems associated with selfplagiarism and duplicate publication in the humanities (Bruton et al. 2020), or the extent to which the main philosophy journals comply with basic editorial standards-with somewhat disheartening results (Polonioli 2017).

As some scholars have noted, philosophers and ethicists have played a vital role in discussions on research ethics in other disciplines, but have paid less attention to the potential problems affecting their own fields (Hansson 2017; Hansson 2019; Dougherty 2018). Studies of particular cases of misconduct have revealed that "ethics is not always conducted ethically" (Hansson 2017, 106), but how widespread is research misconduct in ethics and philosophy? The aim of this study, although limited to the Spanish context, is to help bridge this gap in the literature.

The numerous studies on research misconduct have shed light on the situation in western countries — predominantly English-speaking countries- (Fanelli 2009; Pupovac and Fanelli 2015), although in recent years research interest has also reached other geographical contexts (Okonta and Rossouw 2013; Ana et al. 2013; Okonta and Rossouw 2014; Rohwer et al. 2017; Felaefel et al. 2018; Liao et al. 2018; AtaieAshtiani 2018). Very little research has examined the extent of misconduct in Spain, however. Only one study specifically analyses research misconduct in the social sciences, focusing on editors' perceptions of its extent in the fields of communication, education and psychology (Fonseca-Mora et al. 2014). Other more recent papers analyse the number of retracted papers in the field of biomedicine (Dal-Ré 2020; Marco-Cuenca et al. 2019). 
Several studies on research misconduct identify pressure to publish as one of the factors that can influence researchers' ethical behaviour. This pressure is a consequence of policies that evaluate researchers' performance primarily on the basis of the number of papers they publish and their impact measured by citation frequency (De Vries et al. 2006; Delgado-López-Cozar et al. 2007; John et al. 2012; Martin, 2013; Okonta and Rossouw 2013; Tijdink et al. 2014; Pupovac et al. 2017; Liao et al. 2018; Felaefel et al. 2018; Maggio et al. 2019; Holtfreter et al. 2019).

Spain is a paradigmatic example of such policies. Since 1989, research performance has been evaluated according to the number of publications and their impact calculated by the number of citations (Jiménez-Contreras et al. 2003; JiménezContreras et al. 2002; Ruiz-Pérez et al. 2010). These policies were first applied in the area of experimental sciences (Jiménez-Contreras et al. 2003; Butler 2004; Hicks 2012; Derrick and Pavone 2013) and have gradually been introduced into the humanities, especially in the last decade (Marini 2018). Spain has two main instruments for evaluating research performance: the sexenio (recognition of research performance assessed by committee every six years), and the acreditación ('habilitation' for promotion). The first process is rewarded by a productivity bonus in the researcher's salary and is administered by the National Commission for the Evaluation of Research Activity (CNEAI) (Cruz-Castro and Sanz-Menéndez 2007). The second evaluation, undertaken by the National Agency for Quality Assessment and Accreditation (ANECA), determines researchers' chances of promotion. The existence of this longstanding policy allows us to also explore the perception among Spanish ethics and philosophy researchers of a possible relationship between this type of evaluation model and their ethical conduct.

In sum, this study sets out to uncover the perceptions held by Spanish ethics and philosophy researchers on the prevalence of research misconduct and the possible influence of Spain's performance evaluation policy on such practices.

\section{Methods}

In this study we apply triangulation methodology comprising a self-administered questionnaire, a debate held at the annual meeting of scientific association, and 14 indepth interviews. These three data-gathering techniques yielded quantitative and qualitative information about research misconduct. The questionnaire provided quantitative data on the opinions of academics and researchers working in the areas of ethics and philosophy in Spanish universities and research centres. The debate allowed us to contrast and corroborate some of the findings from the questionnaire, discuss their reliability, and prepare the interviews. Finally, the interviews provided the opportunity for more in-depth exploration of the interviewees' knowledge about the types of misconduct perceived by the research community and how they might be related to the evaluation system.

\section{Self-administered questionnaire}

The study population comprised university researchers and faculty working in the knowledge areas of philosophy and ethics in Spain, together with researchers from the Institute of Philosophy at the Spanish National Research Council (CSIC). We identified the members of this academic community through a systematic search of the websites of Spanish universities that have teaching faculty and researchers in these knowledge fields. We looked first at departmental websites, and in their absence, faculty or school 
websites, or the universities' general directories, and compiled a list of the knowledge area and email address of each researcher or faculty member. In the vast majority of institutions (with only four exceptions) we were able to identify the faculty members affiliated with the areas of philosophy and ethics.

Through these inquiries we identified 541 faculty members and researchers, of whom 521 worked in universities and 20 in the CSIC; 44 universities (37 public and seven private) took part in the study and responses were received from all but three institutions. Table 1 shows the distribution by knowledge area. Although representatives from both fields were surveyed, they did not respond in the same proportion. The overall response rate was $37.1 \%$, but responses from the area of ethics accounted for $52.8 \%$ compared to $30.5 \%$ from philosophy.

Table 1. Demographics of the survey of Spanish university faculty and researchers in philosophy and ethics

\begin{tabular}{|l|c|c|c|}
\hline \multicolumn{1}{|c}{ FIELD } & \multicolumn{2}{c}{$\begin{array}{c}\text { Total } \\
\text { population }\end{array}$} & \multicolumn{2}{c|}{ Respondents } & $\begin{array}{c}\text { Average } \\
\text { response } \\
\text { rate }\end{array}$ \\
\hline Philosophy & 380 & 115 & $30.5 \%$ \\
\hline Ethics & 161 & 86 & $52.8 \%$ \\
\hline Total & 541 & 201 & $37.1 \%$ \\
\hline
\end{tabular}

The data was collected using Google Forms and respondents were asked about their affiliation and employment situation. The questions were divided into four main sections: 1) information search behaviour, 2) communication practices, 3) scientific evaluation, and 4) ethics in scientific publication, the latter being the main focus of the present study. This section aimed to uncover the prevalence of misconduct and how it might be affected by the evaluation system applied in Spain.

The questionnaire asked the respondents to give their impressions of various forms of publication misconduct, including duplicate publication, self-plagiarism, plagiarism, data fabrication or falsification, use of personal influence, pressure on editors and false authorship. No limit was placed on the number of misconduct types they could select. We asked about the general behaviour of the respondents' research community rather than their individual behaviour, which is usually measured with a different parameter (Pupovac and Fanelli 2015). This questionnaire item was worded as follows: Indicate whether you think any of the following forms of misconduct in scientific publication are currently on the increase (Choose more than one option if necessary).

The question on the effect of the evaluation model was worded as follows: To what extent do you think the evaluation and promotion systems applied to Spanish researchers are affecting their ethical behaviour? The respondents were asked to choose between very much, quite a lot, a little, not at all or no answer.

The questionnaire included an open question where respondents could freely express their opinions on the object of study. The 60 responses we obtained to this question provided qualitative data in the survey stage of the research. Of these responses, 10 were directly linked to research ethics or research misconduct, and were codified using the same structure as for the interviews (see Table 2) but with -s (denoting survey) instead of -i (interview) (LE1-s, LPh1-s, LPh7-s, SlPh1-s, SlPh6-s, SIPh8-s, SIPh11-s, SIE2-s, PE2-s, PE3-s).

The online survey remained open for responses between February and June 2019. On 25 February, a message was sent to the institutional email address of the 541 
faculty members and researchers identified, followed by two reminders, two weeks and four weeks after the initial contact. We also approached the main scientific societies and associations for Spanish philosophy professionals - the Spanish Association for Ethics and Political Philosophy (AEEFP), the Academic Society of Philosophy (SAF) and the Spanish Philosophy Network (REF) - requesting their collaboration. In May, these organisations contacted their members by email to encourage them to participate in the survey. The survey was closed on 14 June 2019.

\section{Debate at the annual meeting of a scientific society}

On 30 May 2019, the authors of this study participated in a debate during the annual meeting of the Spanish Association for Ethics and Political Philosophy (AEEFP), held in the Institute of Philosophy at the CSIC (Madrid). ${ }^{4}$ The debate lasted 65 minutes and contributions to the discussion from 26 researchers were transcribed for subsequent analysis. This qualitative information came from researchers working in a number of different universities and with diverse academic careers, from research fellows to full professors; a wide range of profiles, affiliations and opinions on research misconduct was therefore represented. Their contributions provided valuable input in preparing the in-depth interviews, the final stage of the research.

\section{Interviews}

The interviews took place in September and October 2019. The 14 interviewees were selected according to the criteria of affiliation, professional category, gender and disciplinary area in order to guarantee the widest possible range of profiles. Seven of the interviewees were men and seven were women, and seven worked in the field of ethics and seven in philosophy. Verbal informed consent was obtained prior to each of the interviews.

Table 2. List of university faculty and researchers in philosophy and ethics interviewed according to career position

\begin{tabular}{|l|l|l|l|}
\hline $\mathbf{N}^{\mathbf{o}}$ & Career position & Area & Code \\
\hline 1 & Research fellow & E & RfE1-i \\
\hline 2 & Research fellow & E & RfE2-i \\
\hline 3 & Research fellow & $\mathrm{Ph}$ & RfPh1-i \\
\hline 4 & Lecturer & $\mathrm{Ph}$ & LPh1-i \\
\hline 5 & Lecturer & $\mathrm{Ph}$ & LPh2-i \\
\hline 6 & Senior lecturer & $\mathrm{Ph}$ & $\mathrm{SlPh} 1-\mathrm{i}$ \\
\hline 7 & Senior lecturer & $\mathrm{Ph}$ & $\mathrm{SlPh} 2-\mathrm{i}$ \\
\hline 8 & Senior lecturer & $\mathrm{Ph}$ & $\mathrm{SlPh} 3-\mathrm{i}$ \\
\hline
\end{tabular}

\footnotetext{
${ }^{4}$ The programme (in Spanish) is available at https://aeefp.site123.me/actividades-1/jornadas-de-la-aeefp and at https://redfilosofia.es/wp-content/uploads/2019/05/Jornada_AEEFP.pdf
} 


\begin{tabular}{|l|l|l|l|}
\hline 9 & Senior lecturer & E & SlE1-i \\
\hline 10 & Senior lecturer & E & SlE2-i \\
\hline 11 & Professor & Ph & PPh1-i \\
\hline 12 & Professor & E & PE1-i \\
\hline 13 & Professor & E & PE2-i \\
\hline 14 & Professor & E & PE3-i \\
\hline
\end{tabular}

The interviewees were affiliated to the universities of Barcelona, Castellón, Complutense (Madrid), Granada, Murcia, Valencia, Zaragoza and the Basque Country, as well as the Institute of Philosophy at the CSIC. The semi-structured interviews lasted an average of 35.30 minutes; the shortest was 14.14 minutes and the longest, 59.10 minutes. The interviews were then transcribed for analysis.

The questions were as follows: 1. Do you think there is misconduct in your research area? And if so, 2. Which misconduct practices do you consider to be the most prevalent in your knowledge area? On this occasion, we used an open question format so as to minimise possible interviewer influence and to contrast the data obtained in the survey, in which the same question was posed in a closed format.

\section{Results}

\section{On research misconduct}

The vast majority of the Spanish university faculty in the areas of ethics and philosophy $(91.5 \%)$ considered research misconduct to be on the increase; $63.2 \%$ identified three or more of the eight fraudulent practices highlighted in the study, and $84.1 \%$ noted two or more (Table 3).

Table 3. Number of research misconducts considered prevalent by Spanish university faculty and researchers in the fields of philosophy and ethics

\begin{tabular}{|l|r|r|r|r|r|r|}
\hline \multicolumn{1}{c}{$\begin{array}{c}\text { Number of research } \\
\text { misconducts }\end{array}$} & \multicolumn{2}{c}{ Total } & \multicolumn{2}{c}{ Philosophy } & \multicolumn{2}{c|}{ Ethics } \\
\hline One & 15 & 7.5 & 10 & 8.7 & 6 & 7.0 \\
\hline Two & 42 & 20.9 & 26 & 22.6 & 16 & 18.6 \\
\hline Three & 54 & 26.9 & 23 & 20.0 & 31 & 36.0 \\
\hline Four & 35 & 17.4 & 26 & 22.6 & 8 & 9.3 \\
\hline Five & 15 & 7.5 & 6 & 5.2 & 9 & 10.5 \\
\hline Six & 14 & 7.0 & 8 & 7.0 & 6 & 7.0 \\
\hline Seven & 4 & 2.0 & 2 & 1.7 & 2 & 2.3 \\
\hline Eight & 5 & 2.5 & 3 & 2.6 & 2 & 2.3 \\
\hline no response & 17 & 8.5 & 11 & 9.6 & 6 & 7.0 \\
\hline Total & 201 & 100.0 & 115 & 100.0 & 86 & 100.0 \\
\hline
\end{tabular}

The most prevalent forms of misconduct identified were duplicate publication $(66.5 \%)$ and self-plagiarism $(59.0 \%)$, which were mentioned by almost two thirds of the survey respondents (Figure 1). By contrast, plagiarism was considered to be a less frequent practice, only noted in $28.5 \%$ of the responses. The use of personal influence to smooth the path to publication was the third most commonly mentioned misconduct 
(57.5\%). The perception of citation manipulation can also be regarded as high $(44.0 \%)$, whether in the form of excessive self-citation, or through premeditated mutual citation among groups and researchers designed to increase the impact of specific journals or authors. Finally, less common fraudulent practices were false authorship - ghost or honorary authors - $(20.5 \%)$ and the fabrication or falsification of data $(10.0 \%)$.

Figure 1. Prevalence of research misconduct in publishing among Spanish university faculty and researchers in the fields of philosophy and ethics

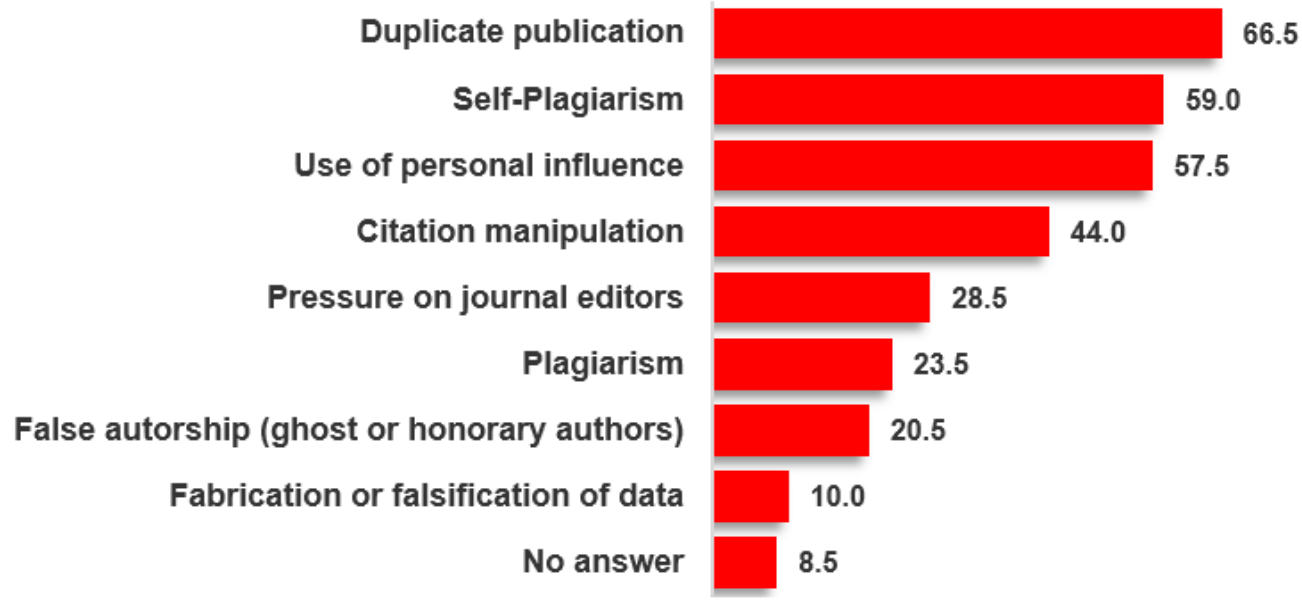

We found no significant differences between the two knowledge areas with regard to the prevalence of research misconduct in publication (Figure 2). In general, misconduct was found to be slightly higher in ethics than in philosophy, with just two exceptions: duplicate publication (68.7\% in philosophy), and pressure on journal editors to favour or smooth the path to publication $(31.3 \%)$.

Figure 2. Prevalence of research misconduct in publishing among Spanish university faculty and researchers in the fields of philosophy and ethics according to discipline

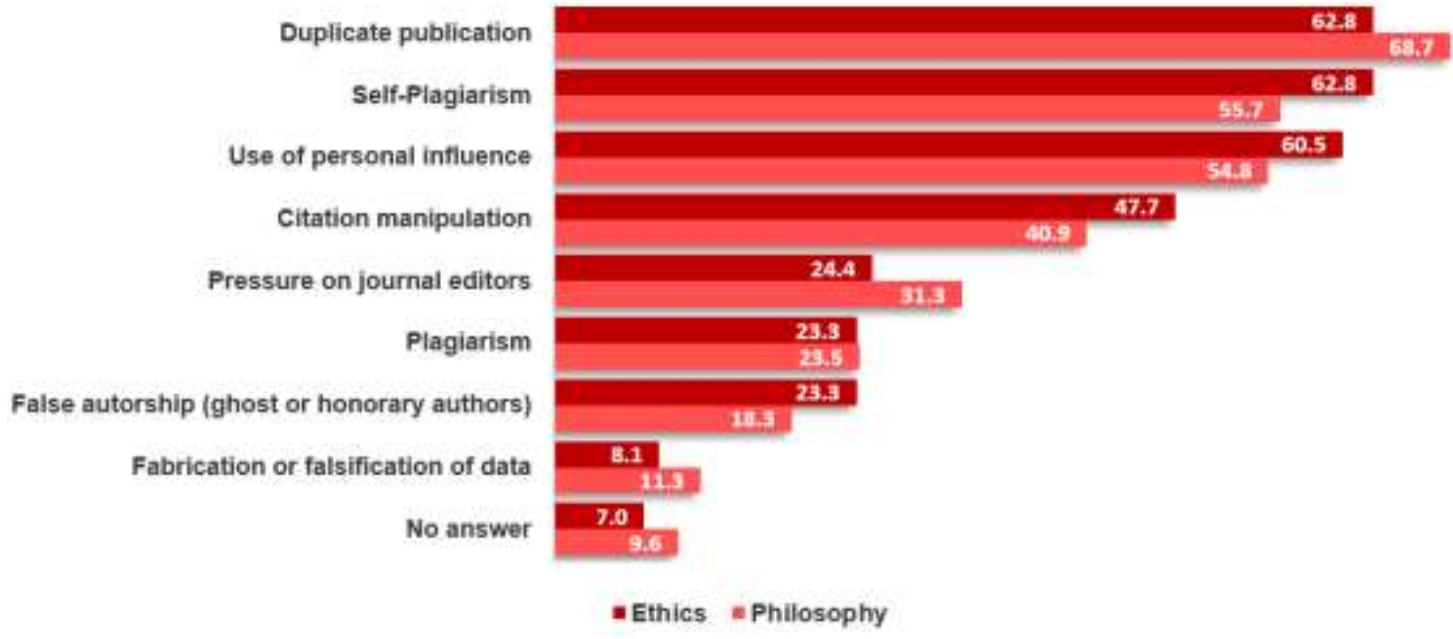

The qualitative information in the study, obtained from the open question in the survey, the debate and the interviews, provides a more detailed picture of the extent and deepness of misconduct in the research community, and corroborates the results of the 
survey. Three problems were expressly highlighted in the debate: duplicate publication, self-plagiarism, and plagiarism; the first two of these malpractices were identified as the most prevalent in this field both in the survey and in the debate, where they sparked discussion on the need for plagiarism detection software and its usefulness and limitations.

In the interviews, the vast majority of the participants expressed the view that inappropriate research practices were becoming more widespread. Only one interviewee (SlPh2-i) stated that although some misconduct can be "assumed" to exist, research is carried out "strategically but, in general, honestly"; this interviewee was also the only person who did not perceive an escalation in any type of research misconduct. By contrast, the other 13 interviewees defined at least one type of research misconduct as an increasing problem, particularly self-plagiarism. The opinions gathered in the interviews differed from the survey results in that fewer interviewees identified more than three types of research misconduct, although a high percentage ( 8 of the 14 interviewees) reported two or more. Two interviewees mentioned five types and another one, three types of misconduct. A further five said they were aware of two different widespread practices and in total, five interviewees mentioned one case of widespread unethical conduct. The youngest interviewees referred to a narrower range of unacceptable research practices; two interviewees identified one form of misconduct and another specified two forms (see Table 3).

Up to nine different types of inappropriate practices were mentioned in the interviews. The most frequently noted was self-plagiarism, which was referred to in eight of the interviews and by three participants in the debate. This was followed by plagiarism, segmented or 'salami' publication and creating groups for mutual citation, each of which were mentioned four times. Duplicate publication was referred to in three interviews and excessive self-citation in two. This issue was also mentioned by three respondents (SIPh6-s, SIPh11-s, PE2-s) in the open question of the survey. Finally, a series of other practices were mentioned only once in the interviews: data falsification, fraudulent delegation of teaching to younger colleagues, and inclusion of references not used in the research.

Table 4. Number and type of misconduct mentioned by Spanish university faculty and researchers in the fields of philosophy and ethics in the interviews

\begin{tabular}{|c|c|c|}
\hline Interviewee & $\begin{array}{l}\text { Number of } \\
\text { misconducts } \\
\text { mentions }\end{array}$ & Types of misconduct identified \\
\hline RfE1-i & 1 & Self-plagiarism \\
\hline RfE2-i & 2 & Self-plagiarism and duplicate publication \\
\hline RfPh1-i & 1 & Fraudulent delegation of teaching to younger colleagues \\
\hline LPh1-i & 2 & Self-plagiarism, salami publishing \\
\hline LPh2-i & 2 & Plagiarism and creation of groups for mutual citation \\
\hline SlPh1-i & 5 & $\begin{array}{l}\text { Self-plagiarism, duplicate publication, salami publishing, groups } \\
\text { for mutual citation, excessive self-citation }\end{array}$ \\
\hline SlPh2-i & 0 & No specific type of misconduct mentioned \\
\hline SlPh3-i & 5 & $\begin{array}{l}\text { Self-plagiarism, salami publishing, duplicate publication, } \\
\text { introducing unused references, and groups for mutual citation }\end{array}$ \\
\hline SlE1-i & 3 & Self-plagiarism, plagiarism, salami publishing \\
\hline SlE2-i & 2 & Excessive self-citation and data falsification \\
\hline PPh1-i & 1 & Self-plagiarism \\
\hline PE1-i & 1 & Creation of groups for mutual citation \\
\hline
\end{tabular}




\begin{tabular}{|l|l|l|}
\hline PE2-i & 2 & Self-plagiarism, plagiarism \\
\hline PE3-i & 1 & Plagiarism \\
\hline
\end{tabular}

The interviewees not only identified the types of misconduct they regarded as widespread, but also gave their interpretations of these practices. Some of the most significant statements are provided below:

The most obvious are self-plagiarism, plagiarism. Repeating other [scholars'] ideas and passing them off as one's own. SlE1-i

I think one of them [misconducts] is the practice of publishing practically the same thing in different places, journals, book chapters..., practically the same idea with just a few changes but some paragraphs word for word. I've read people who have said practically the same thing in seven different places. I regard this as misconduct because it undermines the originality of what you publish and of the research. RfE2-i

[...] salami slicing a single study into various papers to add more weight to an academic curriculum, repeating time and again the same subject with slight variations, publishing the same thing ten times in ten different places. SIPh1-i

They stretch things out too much LPh1-i

[...] my colleagues and everyone else admit it. You can't be saying something new every five minutes. If you have to publish one or two papers each year, you repeat things with slight variations $[\ldots] . \mathrm{PPh} 1-\mathrm{i}$

The honesty of the interviewees is noteworthy; several of them openly expressed their doubts about the way they do research or acknowledged having occasionally committed some form of misconduct. This is particularly relevant since researchers tend to overestimate misconduct among their colleagues, but play down their own questionable practices (Pupovac and Fanelli 2015). Some of the statements were especially illuminating in this respect:

Self-plagiarism is curious... one always self-plagiarises because one starts with what one has said previously. But the intention is to take the research forward and not simply repeat what you've said before, but in a different way. I may do it myself on occasions [...] SlE1-i

I have work published in [...] that is "rehashed" from things I published earlier in Spain. SlPh3-i

About plagiarism or self-plagiarism... I sometimes self-plagiarise, for example on the subject of freedom in [...] because I can't come up with anything new when I go to a research conference. I don't present it in evaluations afterwards, but yes, I do self-plagiarise. PE2-i

I'm not against self-plagiarism because I do it myself. When you've written something, you take bits from one place, put them all together and it's useful for something else. PE3-i

The interviews corroborated the main trends identified in the survey. Including the open question in the survey may have reduced the number of types of misconduct respondents identified, but it did allow them to mention other types of misconduct that were not listed in the closed question. Self-plagiarism was the main problem mentioned in the interviews, an issue also widely recognised in the survey. The interviewees referred less to duplicate publication, which was the most widely noted misconduct in the survey, although this may be because the two practices are closely related and may be considered as different degrees of the same phenomenon (Bruton 2014). In turn, when asked about types of misconduct in the interview, it is striking that none of the 
interviewees referred to the use of personal influence in publication processes, despite this practice being recognised by $57.5 \%$ of the survey respondents. However, when we asked the interviewees about the implementation of peer review in their respective fields, they repeatedly mentioned how it was manipulated for the purposes of research performance evaluations. The comments followed two broad lines: the use of peer review to benefit likeminded authors (PE1-i and PE3-i); and as a mechanism to censure authors with divergent approaches or methodologies to one's own (RfE1-i, LPh1-i, LPh2-i, PPh1-i, PE3-i). Finally, it is somewhat surprising that plagiarism was one of the most frequently mentioned practices in both the interviews and the debate, although it was referred to by only $23.4 \%$ of the survey participants.

The researchers' views on the manipulation of citations are also noteworthy. This subject was referred to by five of the interviewees, both in terms of excessive selfcitation (SIPh1-i, SlE2-i), and the possible creation of citation cartels (LPh2-i, SIPh1-i, SlPh3-i, PE1-i,) with the aim of raising impact factors. The following extracts from the interviews reflect their observations:

Yes. For example, the fact that impact is measured by citations. So a 'lobby' of friends is set up to cite each other's papers and they gradually rise in the Google Scholar statistics, not because the paper is actually exceptional or has set a new milestone, but because of collusion to increase its impact. LPh2-i

You've got to be fairly brazen to do that, I mean continually citing yourself...it's pretty shameless behaviour. I don't know if in some way you're forced into doing it to follow an academic career, because if you aren't credited or you don't get favourable evaluations for your work... SlE2-i

The difference between high impact and low impact journals, what is it, twenty citations? We can fix that, you and me agree to cite each other and we tell people to cite that journal and in a year we've raised its impact... SIPh3-i

In the end it's an attempt to exploit the research or match it to those criteria, which leads to phenomena like citing each other to increase the impact [...]. In the end, we're in a profession where it's not easy to secure a position, tenure, contracts, grants, so these types of practices proliferate. PE1-i.

These statements testify to the impact of the Spanish research performance evaluation system, which assesses research excellence by counting the number of citations received by a journal (impact factor), by a researcher (h-index) or by a publication (number of citations). This criterion is used in both faculty promotion (acreditación) and the productivity bonus (sexenio) processes. The next section examines this issue in greater depth.

\section{The research performance evaluation model and research misconduct}

The overwhelming majority $(90.5 \%)$ of the survey respondents considered that the research performance evaluation model affects research misconduct 'quite a lot' or 'very much'. In the case of philosophy scholars, this percentage rose to $94.8 \%$ while among ethics researchers it was slightly lower at $84.9 \%$ (Figure 3). These results are highly convincing since only one of the 201 researchers surveyed contended that the evaluation system had no effect at all on ethical behaviour. 
Figure 3. Spanish philosophy and ethics researchers' opinions on the effect of the evaluation and promotion systems on their ethical behaviour according to discipline

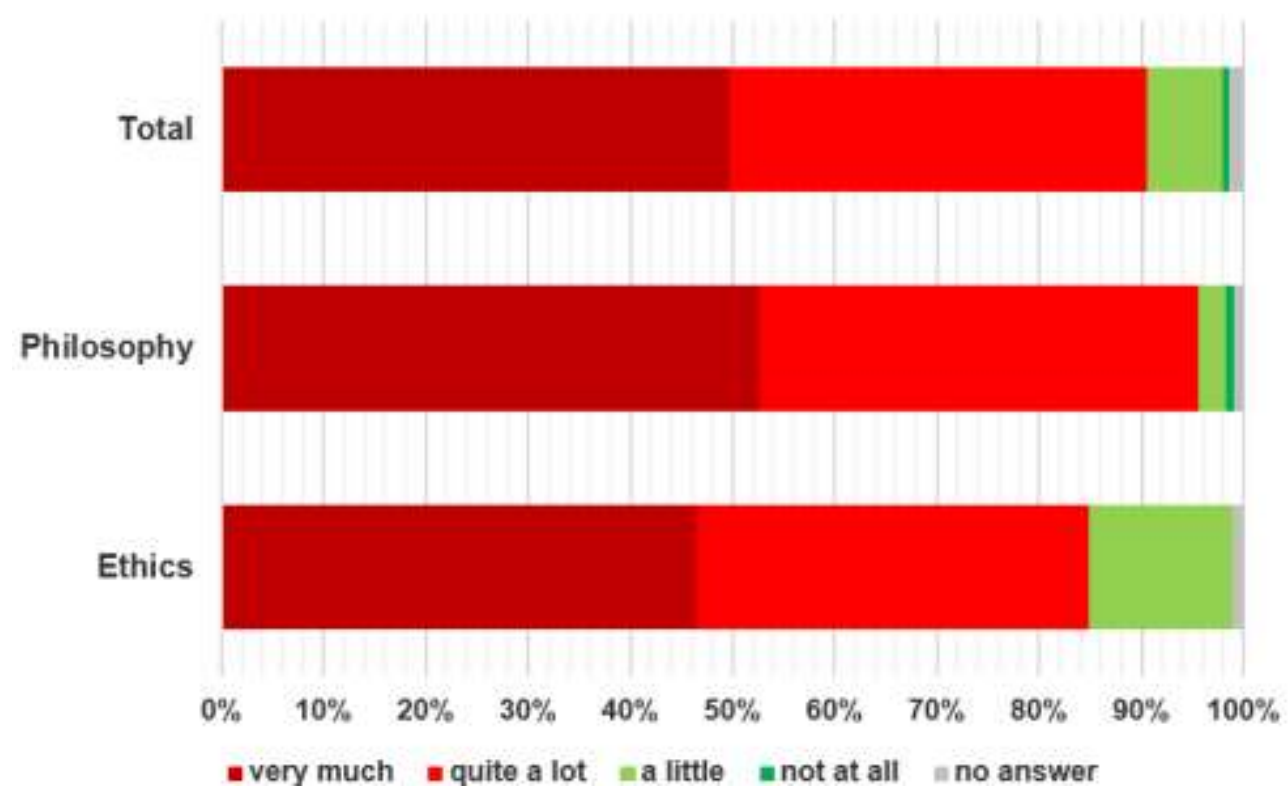

The qualitative information gathered in this study sheds more light on these data. The interviewees associated the proliferation of research misconduct with "the current model" of evaluation. It is important to note that the researchers themselves made this connection, as no direct question was asked in the interview. When they responded to the question on the prevalence of misconduct, they spoke at length about the evaluation system, which they viewed as inseparable from the problem of misconduct. In total, 10 interviewees made this association and only the three youngest researchers (who started their academic career under the new system and had known no alternative, RfE1-i, RfE2-i, RfPh1-i) and one senior lecturer (who did not perceive any specific misconduct as widespread, SlPh2-i) did not make this point. The interviewees explained this association in different terms. Some attributed it to aspects such as the "pressure to publish" (PPh1-i, PE2-i, PE3-i), others to the introduction of "quantitative evaluation" of merit (SlPh1-i, SIPh3-i) or to the dynamics caused by "the system" (SlE1-i, LPh2-i). Finally, others consider that in a competitive environment the "survival instinct" drives the proliferation of research misconduct (LPh1-i, SlE2-i, PE1-i).

Opinions expressed in the open question of the survey also linked the increase in misconduct with the evaluation system. Seven responses reflected these views, mentioning above all the pressure the system exerts on researchers' careers (LE1-s, LPh1-s, LPh7-s, SIPh1-s, SlPh8-s, SlE2-s, PE3-s).

The following verbatim extracts from the interviews and the open question are especially enlightening on the reasons driving research misconduct:

If you have to publish one or two papers every year, you repeat things with slight variations... the pressure to publish has this effect. And, consequently, there's an increase in the number of publications that really add nothing, nor contribute anything to the scholarship. Mediocracy runs through many publications. [...] But there's this pressure to accumulate points. PPh1-i

I've seen [the effects of] this pressure on people I know. This pressure to publish more papers has pushed them to be dishonest in this respect. PE3-i 
Authors should undoubtedly improve their publication practices [...], but the poor conception of evaluation and the pressure to which researchers are subject do not exactly help... PE3-s

[...] many people are looking for ways round the system. But obviously, if you actively pursue a weighty CV, then that's what you get. SIPh1-s

The current publication evaluation system is leading to bad habits and corruption among young researchers that are degrading the quality of university faculty. SIPh1-s

The system is becoming corrupted as a result of the excessive importance placed on impact factors and other parameters that have absolutely no place in research in areas like philosophy or ethics. SlPh8-s

The bad thing, it seems, is that the researcher is generally conditioned by such criteria. $\mathrm{LPh} 7-\mathrm{s}$

When evaluation is purely quantitative, this is what happens [...] misconduct arises. SLPh3-i

How can this [referring to plagiarism and self-plagiarism] be resolved? Perhaps by changing the ANECA criteria and evaluating quality more than quantity. SlE1-i

Well... researchers do it because the system is pushing them to do so. But it is misconduct. Because it doesn't reflect the real quality on one hand. And on the other, the question of plagiarism. Because one has to produce so much, some people will plagiarise your work. I've been plagiarised. $\mathrm{LPh} 2-\mathrm{i}$

It's a question of publishing more, more quickly, not to be better, but simply to exist and survive. LPh1-i

Short-termism, wanting to publish quickly and, on top of that, with a high impact [...] means some research lines are lost in favour of more productive ones. That is, research is done not on what is most relevant, or of scientific or social interest, but on what allows us to get ahead in academic life. SIE2-i

Publication practices are determined by the need for scientific evaluation, for access to a professional, teaching and research career. LE1-s

\section{Discussion}

The main finding of this study is the widespread perception of research misconduct in the areas of ethics and philosophy in Spain. Of the faulty and researchers who participated in this research, $91.5 \%$ consider that research misconduct is on the rise. The $52.8 \%$ response rate from the field of ethics and 30.5\% from philosophy suggest that our findings are highly representative of the Spanish scientific community.

The data on research misconduct gathered in different contexts and disciplines vary substantially according to what is being asked, how it is asked, and to whom (John et al. 2012; Pupovac and Fanelli, 2015; Godecharle et al. 2018; Felaefel et al. 2018). Thus, in Fanelli's (2009) meta-analysis of survey data, significant differences were found depending on whether researchers were asked about their own behaviour, that of their colleagues, or across their discipline as a whole. Indeed, Fanelli (2009) found that "on average, about $2 \%$ of scientists admitted to have fabricated, falsified or modified or results [...] at least once and up to one third admitted a variety of other questionable research practices" $(2009,8)$. However, when they were asked about their colleagues' behaviour, "fabrication, falsification and modification had been observed, on average, by over $14 \%$ of respondents, and other questionable practices by up to $72 \%$ " (Fanelli, $2009,8)$. Given that our study asked about perceptions of research misconduct, the high 
percentages we found appear reasonable. Moreover, our data are similar to those of other studies that examine perceptions of research misconduct among colleagues in a range of disciplines (Faleafel et al. 2018; Okonta and Rossouw 2014). The novel contribution of this study is its empirical approach in the areas of ethics and philosophy.

Likewise, results can be affected by the approach taken in studying research misconduct, whether more specifically-only considering the most serious 'FFP' (falsification, fabrication and plagiarism) practices-or more broadly, including "mundane misbehaviour" (Martinson et al. 2005; De Vries et al. 2006; Haven et al. 2019a). The three elements of FFP, the focus of numerous studies of research misconduct, are not predominant in the disciplines examined in this study. This is unsurprising, since the pattern we uncovered is typical of humanistic disciplines, and in fact aspects of our findings coincide with those of other studies. It makes sense, for instance, that the fabrication or falsification of data will be less frequent in the humanities, which do not typically follow empirical or quantitative approaches in their research (Pupovac et al. 2017). The high rates of duplicate publication, self-plagiarism and plagiarism reported in our study coincide with the problems typically associated with philosophy due to the difficulty of drawing clear red lines in these aspects (Bruton 2014; Hansson 2008; Hansson 2017; Dougherty, 2018; Haven et al. 2019a). Indeed, the results we obtained on perceived duplicate publication $(66.5 \%)$ are similar to those in Bretag and Carapiet's (2007) preliminary study of social sciences and humanities disciplines in Australia. Their research, using a textmatching software program, found that $60 \%$ of the authors in their sample had "committed self-plagiarism in at least one of their published papers in the period 2003-2006" (Bretag and Carapiet 2007, 92). These authors also observed that " $70 \%$ of authors used 'cut and paste' textual re-use" (Bretag and Carapiet 2007, 100). In turn, the multidisciplinary study conducted by Haven and colleagues also found that the second most frequent research misconduct in the field of humanities was the "use [of] published ideas or phrases of others without referencing" (Haven et al. 2019a, 6).

One aspect in which our results differ is the researchers' perceptions of the extent of citation manipulation in fields of the humanities. This phenomenon may be explained by the nature of the Spanish evaluation system, in which the number of citations an individual researcher obtains is now crucial to their career advancement prospects. Although we have no specific data from the humanities with which to compare the findings of our research, one Spanish study of the social sciences-communication, education and psychology-measured the impact of research misconduct associated with citation. This study analysed editors' perceptions of 16 inappropriate practices, finding that the most frequent were related to manipulation of citations-excessive self-citation of the journal (66.7\%), coercion by editors to cite papers from their journal (45.7\%) and mutual citation (44.4\%) (Fonseca-Mora et al. 2014). The result for coercion to cite and mutual citation is very similar to that found in our study $(44.0 \%)$.

The qualitative part of our study also provided valuable information on types of misconduct. The participants' honesty and the doubts they expressed about their own ethical behaviour are particularly noteworthy. The qualitative aspects of the study also raised certain doubts about the definition of research misconduct typologies, confirming cautions voiced by other authors in reference to the field of philosophy (Hansson 2019; Dougherty 2018). The researchers were more aware of the ethical limits in other disciplines than those directly affecting their own research work, although this did not prevent them from expressing a critical awareness of the types of misconduct that affect their own area. 
A final relevant point is the way Spanish ethics and philosophy faculty and researchers perceive the decisive role that the evaluation system, based on publication and citation counts, plays in researchers' ethical behaviour. The literature has long warned that the pressure to publish may be a trigger for research misconduct (De Vries et al. 2006; Delgado López-Cozar 2010; Fanelli 2010; John et al. 2012). Notable studies provide hard data on the potential impact of evaluation systems (Okonta and Rossouw 2013; Tijdink et al. 2014; Pupovac et al. 2017; Liao et al. 2018; Felaefel et al. 2018; Maggio et al. 2019). Even studies that question this direct relationship, such as Fanelli, Costas and Larivière (2015), and advocate demythifying this causal relationship, have observed that in countries where cash incentives are used to raise performance, the "likelihood of a retraction was higher" $(2015,9)$. The ethics and philosophy researchers in this study in Spain, a country that applies such rewards through sexenios, are quick to warn of the consequences the current system has for ethical behaviour, both in the questionnaire $(90.5 \%$ of the respondents considered the two to be fairly or very closely related) and in the qualitative part of the study. The interviews confirmed the close link between evaluation models and misconduct: participants attributed these unacceptable practices directly to the "system" or to "pressure", stating that researchers adapt to the conditions they work under, which also entails adapting their ethical behaviour.

The most significant conclusion to be drawn from our study is not only that research misconduct is prevalent and is associated with the evaluation model, but that these data apply to the fields of philosophy and ethics. To our knowledge, this is the first study at a global level to provide empirical evidence on research misconduct in these disciplines. The philosopher or ethics researcher is a "homo academicus" (Bourdieu, 1988) and as such, develops in an environment in which they are subject to the same pressures as all other academics. And strikingly, their cognitive assumptions provide no immunity against such misconduct. Our study confirms that philosophy and ethics researchers suffer the same problems as their colleagues in other disciplines. This is an important but also worrying finding for the future development of research, the way it is carried out, and above all, the way it is evaluated. These data should sound the alarm on the possible consequences of adopting evaluation systems that measure research performance in bibliometric terms and that promote a culture of publish or perish, since such policies are the most effective way to fuel the proliferation of research misconduct.

\section{References}

Ana, J., Koehlmoos, T., Smith, R., \& Yan, L. (2013). Research Misconduct in Low- and Middle-Income Countries. Plos Medicine, 10(3), e1001315, https://doi.org/10.1371/journal.pmed.1001315

Anderson, M. S., Ronning, E. A., De Vries, R., \& Martinson, B. C. (2007). The perverse effects of competition on scientists' work and relationships. Science and engineering ethics, 13(4), 437-461, Doi: 10.1007/s11948-007-9042-5

Ataie-Ashtiani, B. (2018). World map of scientific misconduct. Science and engineering ethics, 24(5), 1653-1656, Doi: 10.1007/s11948-017-9939-6.

Bailey, C. D. (2019). Unethical Practices by Accounting Researchers: Incidence, Intentions, and Insights, SSRR, http://dx.doi.org/10.2139/ssrn.3501602

Bedeian, A. G., Taylor, S. G., \& Miller, A. N. (2010). Management science on the credibility bubble: Cardinal sins and various misdemeanors. Academy of Management Learning \& Education, 9(4), 715-725, https://doi.org/10.5465/AMLE.2010.56659889

Bretag, T., \& Carapiet, S. (2007). A preliminary study to identify the extent of self-plagiarism in Australian academic research. Plagiary 2(5), 92-103. 
Bourdieu, P. (1988). Homo academicus. Stanford: Stanford University Press.

Bruton, S. (2014). Self-Plagiarism and Textual Recycling: Legitimate Forms of Research Misconduct. Accountability in Research: Policies and Quality Assurance, 21(3), 176197, Doi: 10.1080/08989621.2014.848071

Bruton, S. V., Brown, M., \& Sacco, D. F. (2020). Ethical consistency and experience: An attempt to influence researcher attitudes toward questionable research practices through reading prompts. Journal of Empirical Research on Human Research Ethics, 15(3), 216-226, https://doi.org/10.1177/1556264619894435.

Buljan, I., Barać, L., \& Marušić, A. (2018). How researchers perceive research misconduct in biomedicine and how they would prevent it: A qualitative study in a small scientific community. Accountability in research, 25(4), 220-238, Doi: $10.1080 / 08989621.2018 .1463162$

Butler, L. (2004). What happens when funding is linked to publication counts? In Moed, H., Glänzel, W., \& Smoch, U. (Eds.), Handbook of quantitative science and technology research (pp. 389-405). Dordrecht: Springer.

Cruz-Castro, L., \& Sanz-Menendez, L. (2007). New Legitimation Models and The Transformation of the Public Research Organization Field. International Studies of Management and Organization, 37(1), 27-52. Doi: 10.2753/IMO0020-8825370102

Dal-Ré, R. (2020). Analysis of biomedical Spanish articles retracted between 1970 and 2018. Medicina clínica, 154(4), 125-130, https://doi.org/10.1016/j.medcle.2019.04.033

De Vries, R., Anderson, M. S., \& Martinson, B. C. (2006). Normal misbehavior: Scientists talk about the ethics of research. Journal of Empirical Research on Human Research Ethics, 1(1), 43-50, Doi: 10.1525/jer.2006.1.1.43

Delgado López-Cózar, E. (2010). Claroscuros de la evaluación científica en España. Medes: Medicina en Español, 4, 25-29.

Delgado López-Cózar, E., Torres-Salinas, D., \& Roldán-López, Á. (2007). El fraude en la ciencia: reflexiones a partir del caso Hwang. El profesional de la información, 16(2), 143-150, https://doi.org/10.3145/epi.2007.mar.07

Derrick, G. E., \& Pavone, V. (2013). Democratising research evaluation: Achieving greater public engagement with bibliometrics-informed peer review. Science and Public Policy, 40(5), 563-575, https://doi.org/10.1093/scipol/sct007

Dhingra, D., \& Mishra, D. (2014). Public misconduct among medical professionals in India. Indian Journal of Medical Ethics, 11(2), 104-107, https://doi.org/10.20529/IJME.2014.026

Dougherty, M. V. (2018). Correcting the Scholarly Record for Research Integrity. In the Aftermath of Plagiarism. Cham: Springer.

DuBois, J. M., Anderson, E. E., Chibnall, J., Carroll, K., Gibb, T., Ogbuka, C., \& Rubbelke, T. (2013). Understanding research misconduct: A comparative analysis of 120 cases of professional wrongdoing. Accountability in research, 20(5-6), 320-338, Doi: $10.1080 / 08989621.2013 .822248$

Fanelli, D. (2009). How many scientists fabricate and falsify research? A systematic review and meta-analysis of survey data. PloS ONE, 4(5), e5738, https://doi.org/10.1371/journal.pone.0005738

Fanelli, D. (2010). Do Pressures to Publish Increase Scientists' Bias? An Empirical Support from US States Data. PLoS ONE 5(4), e10271, https://doi.org/10.1371/journal.pone.0010271

Fanelli, D., Costas, R., \& Larivière, V. (2015). Misconduct policies, academic culture and career stage, not gender or pressures to publish, affect scientific integrity. PloS ONE, 10(6), e0127556.

Felaefel, M., Salem, M., Jaafar, R., Jassim, G., Edwards, H., Rashid-Doubell, F., Yousri, R., Ali, N., \& Silverman, H. (2018). A cross-sectional survey study to assess prevalence and attitudes regarding research misconduct among investigators in the Middle East. Journal of academic ethics, 16(1), 71-87, Doi: 10.1007/s10805-017-9295-9 
Fonseca-Mora, M. C., Tur-Viñes, V., \& Gutiérrez-San Miguel, B. (2014). Ética y revistas científicas españolas de Comunicación, Educación y Psicología: la percepción editora. Revista española de documentación científica,37(4), e065, https://doi.org/10.3989/redc.2014.4.1151

Gilbert, F. J., \& Denison, A. R. (2003). Research misconduct. Clinical radiology, 58(7), 499504, https://doi.org/10.1016/S0009-9260(03)00176-4

Godecharle, S., Fieuws, S., Nemery, B., \& Dierickx, K. (2018). Scientists still behaving badly? A survey within industry and universities. Science and engineering ethics, 24(6), 16971717, Doi: 10.1007/s11948-017-9957-4

Grey, A., Avenell, A., Gamble, G., \& Bolland, M. (2019). Assessing and raising concerns about duplicate publication, authorship transgressions and data errors in a body of preclinical research. Science and Engineering Ethics, 26(22), 1-28, https://doi.org/10.1007/s11948019-00152-w

Gross, C. (2016). Scientific misconduct. Annual review of psychology, 67, 693-711, https://doi.org/10.1146/annurev-psych-122414-033437

Hansson, S. O. (2008). Philosophical Plagiarism. Theoria, 74(2): 97-101, https://doi.org/10.1111/j.1755-2567.2008.00010.x

Hansson, S. O. (2015). The Ethics of Doing Philosophy. Theoria, 81(2), 93-96, https://doi.org/10.1111/theo.12067

Hansson, S. O. (2017). The Ethics of Doing Ethics. Science and Engineering Ethics, 23(1), 105-120, https://doi.org/10.1007/s1 1948-016-9772-3

Hansson, S. O. (2019). Philosophical Plagiarism under the Spotlight. Theoria, 85(2), 61-68, https://doi.org/10.1111/theo.12183

Haven, T. L., Tijdink, J. K., Pasman, H. R., Widdershoven, G., Ter Riet, G., \& Bouter, L. M. (2019a). Researchers' perceptions of research misbehaviours: a mixed methods study among academic researchers in Amsterdam. Research Integrity and Peer Review, https://doi.org/10.1186/s41073-019-0081-7.

Haven T. L., Tijdink J. K., Martinson B. C., \& Bouter L. M. (2019b). Perceptions of research integrity climate differ between academic ranks and disciplinary fields: Results from a survey among academic researchers in Amsterdam. PLOS ONE 14(1), e0210599, https://doi.org/10.1371/journal.pone.0210599

Haven, T. L., Bouter, L. M., Smulders, Y. M., \& Tijdink, J. K. (2019c). Perceived publication pressure in Amsterdam: Survey of all disciplinary fields and academic ranks. PloS ONE, 14(6), e0217931, https://doi.org/10.1371/journal.pone.0217931

Hicks, D. (2012). Performance-based university research funding systems. Research policy, 41(2), 251-261, https://doi.org/10.1016/j.respol.2011.09.007

Holtfreter, K., Reisig, M. D., Pratt, T. C., \& Mays, R. D. (2019). The perceived causes of research misconduct among faculty members in the natural, social, and applied sciences. Studies in Higher Education, https://doi.org/10.1080/03075079.2019.1593352.

Hopp, C., \& Hoover, G. A. (2017). How prevalent is academic misconduct in management research?. Journal of Business Research, 80(C), 73-81, https://doi.org/10.1016/j.jbusres.2017.07.003

Horbach, S. S., \& Halffman, W. W. (2019). The extent and causes of academic text recycling or 'self-plagiarism'. Research Policy, 48(2), 492-502, https://doi.org/10.1016/j.respol.2017.09.004

Jefferson, T. (1998). Redundant publication in biomedical sciences: Scientific misconduct or necessity?.Science and Engineering Ethics, 4(2), 135-140, https://doi.org/10.1007/s11948-998-0043-9

Jiménez-Contreras, E., de Moya Anegón, F., \& López-Cózar, E. D. (2003). The evolution of research activity in Spain: The impact of the National Commission for the Evaluation of Research Activity (CNEAI). Research policy, 32(1), 123-142, https://doi.org/10.1016/S0048-7333(02)00008-2 
Jiménez-Contreras, E., López-Cózar, E. D., Ruiz-Pérez, R., \& Fernández, V. M. (2002). Impactfactor rewards affect Spanish research. Nature, 417(6892), 898-898, https://doi.org/10.1038/417898b

John, L. K., Loewenstein, G., \& Prelec, D. (2012). Measuring the prevalence of questionable research practices with incentives for truth telling. Psychological science, 23(5), 524532, https://doi.org/10.1177/0956797611430953

Kokiwar, P. R., Gaiki, V. V., \& Soodi Reddy, A. K. (2020). Prevalence and patterns of research misconduct among medical college faculties. MRIMS Journal of Health Sciences, 8(2), 35-39.

Krstić, S. B. (2015). Research integrity practices from the perspective of early-career researchers. Science and engineering ethics, 21(5), 1181-1196, https://doi.org/10.1007/s1 1948-014-9607-z

Liao, Q. J., Zhang, Y. Y., Fan, Y. C., Zheng, M. H., Bai, Y., Eslick, G. D., He, X. X, Zhang, S. S, Xia, H., \& He, H. (2018). Perceptions of Chinese biomedical researchers towards academic misconduct: a comparison between 2015 and 2010. Science and engineering ethics, 24(2), 629-645, https://doi.org/10.1007/s11948-017-9913-3

Maggio, L., Dong, T., Driessen, E., \& Artino Jr, A. (2019). Factors associated with scientific misconduct and questionable research practices in health professions education. Perspectives on medical education, 8(2), 74-82, https://doi.org/10.1007/s40037-0190501-x

Marco-Cuenca, G., Salvador-Olivan, J. A. \& Arquero-Avilés, R. (2019). Ética en la publicación científica biomedica. Revisión de las publicaciones retractadas en España. El profesional de la información, 28(2), e280222, https://doi.org/10.3145/epi.2019.mar.22

Marini, G. (2018). Tools of individual evaluation and prestige recognition in Spain: how sexenio 'mints the golden coin of authority'. European journal of higher education, 8(2), 201-214, https://doi.org/10.1080/21568235.2018.1428649

Martin, B. R. (2013). Whither research integrity? Plagiarism, self-plagiarism and coercive citation in an age of research assessment. Research Policy, 42(5), 1005-1014, https://doi.org/10.1016/j.respol.2013.03.011

Martinson, B., Anderson, M. \& de Vries, R. (2005). Scientists behaving badly. Nature, 435, 737-738, https://doi.org/10.1038/435737a

Moctezuma, S. E. (2016). Ética en la publicación de revistas académicas: percepción de los editores en ciencias sociales. Innovación Educativa, 16(72), 34-57.

Okonta, P. I., \& Rossouw, T. (2014). Misconduct in research: a descriptive survey of attitudes, perceptions and associated factors in a developing country. BMC medical ethics, 15(1), 25, https://doi.org/10.1186/1472-6939-15-25

Okonta, P., \& Rossouw, T. (2013). Prevalence of scientific misconduct among a group of researchers in Nigeria. Developing world bioethics, 13(3), 149-157, https://doi.org/10.1111/j.1471-8847.2012.00339.x

Polonioli, A. (2017). New Issues for New Methods: Ethical and Editorial Challenges for an Experimental Philosophy. Science and Engineering Ethics, 23, 1009-1034, https://doi.org/10.1007/s1 1948-016-9838-2

Pupovac, V., \& Fanelli, D. (2015). Scientists admitting to plagiarism: a meta-analysis of surveys. Science and engineering ethics, 21(5), 1331-1352, https://doi.org/10.1007/s11948-014-9600-6

Pupovac, V., Prijić-Samaržija, S., \& Petrovečki, M. (2017). Research misconduct in the Croatian scientific community: a survey assessing the forms and characteristics of research misconduct. Science and engineering ethics, 23(1), 165-181, https://doi.org/10.1007/s11948-016-9767-0

Rohwer, A., Young, T., Wager, E., \& Garner, P. (2017). Authorship, plagiarism and conflict of interest: views and practices from low/middle-income country health researchers. BMJ open, 7(11), e018467, http://dx.doi.org/10.1136/bmjopen-2017-018467

Ruiz-Pérez, R., Delgado López-Cózar, E., \& Jiménez-Contreras, E. (2010). Principios y criterios utilizados en España por la Comisión Nacional Evaluadora de la Actividad 
Investigadora (CNEAI) para la valoración de las publicaciones científicas: 1989-2009. Psicothema, 22(4), 898-908.

Stretton S., Bramich N. J., Keys J. R., Monk J. A., Ely J. A., Haley C., Woolley M. J., \& Woolley K. L. (2012). Publication misconduct and plagiarism retractions: a systematic, retrospective study. Current Medical Research and Opinion, 28(10), 15751583, https://doi.org/10.1185/03007995.2012.728131

Tijdink, J. K., Verbeke, R., \& Smulders, Y. M. (2014). Publication pressure and scientific misconduct in medical scientists. Journal of Empirical Research on Human Research Ethics, 9(5), 64-71, https://doi.org/10.1177/1556264614552421

Zwart, H. (2017). Tales of research misconduct. A lacanian diagnostics of integrity challenges in science novels. Switzerland: Springer Nature. 